\title{
Development of prefabricated concrete structures
}

\author{
Weiling Wang \\ Hebei Vocational \& Technical College of Building Materials, Qinhuangdao 066000, China \\ Wangweiling26@163.com
}

Keywords:prefabricated concrete structure,sleeve grouting,grouting anchor connection.

Abstract.Prefabricated concrete structure is composed of prefabricated components assembled on site. Because there are a large number of joint joints between prefabricated components, the joint connection problem of prefabricated components becomes the key to the reliability of prefabricated concrete structure. This paper briefly summarizes the development of prefabricated concrete structure at home and abroad, and points out the research direction of prefabricated concrete structures and the problems to be solved.

\section{Introduction}

Prefabricated concrete structure is a kind of concrete structure with prefabricated concrete components producted by the factory as the main stress components. Prefabricated concrete structures can be prefabricated in factories and assembled in construction sites to realize the industrialization of residential buildings. This paper summarizes and analyzes the research results of domestic and foreign scholars on prefabricated concrete structures, especially the development of prefabricated structures and the method of joint connection between prefabricated components.

\section{Development of prefabricated concrete structures around the world}

Prefabricated concrete structure began in 1920, after the second world war, due to the large number of houses were destroyed, France, the United States, Japan and other countries needed to build a large number of houses in a short time, so housing industrialization began to rise rapidly.

\section{Development of prefabricated concrete structures in Europe}

France is one of the first countries in the world to industrialize construction ${ }^{[1]}$. In 1960, the French construction science and technology center recognized the large-scale plate-type PCa construction method represented by Camus industrial construction method and Coignet construction method. In 1977, ACC was established in France, which further promoted the process of housing industrialization.

Denmark was the first country in the world to adopt the concept of modular in prefabricated concrete structures, so the international organization for standardization (ISO) standarded for modular coordination refer to Danish standards for modular coordination

\section{Development of prefabricated concrete structures in the United States}

The United States began to vigorously promote precast prestressed concrete structures in the $1950 \mathrm{~s}^{[2]}$. The PCI manual edited by the precast/prestressed concrete association which was founded in 1954, summarized the experience in the design and construction of prefabricated concrete structures, which was called the American guide for design and construction of Prefabricated concrete structure.American Concrete institute has published a number of specialized technical documents,such as: ACI550.1 R - 01 "Emulating Cast - in - Place Detailing in Precast Concrete Structures" discusses the design concept of assembly structure and the connection technology of stressed steel bar. "The uniform building code" which was promulgated in 1977 points out that when prefabricated concrete structures are used in high-intensity seismic zones, the capacity, stiffness, ductility and other properties of the structures should not be lower than the cast-in-place structures under the same conditions.In 2012, PCI published "PCI Seismic design of precast and prestressed concrete structures" (MNL - 140), which formulated detailed connection construction requirements , construction technical schemes, quality acceptance specifications, etc.These specifications, which 
combined the construction techniques of the time with the latest scientific research results, had been constantly improved and had played a significant role in promoting the design and engineering application of prefabricated structures.

\section{Development of prefabricated concrete structures in Japan}

In 1966, Japan put forward the Conception of Residential Industrialization and began to promote housing industrialization.In 1969, the industrial technology institute of the ministry of construction of Japan began to implement the "Five-Year Plan for Promoting the Standardization of the Residential Industry".Japan had developed the w-pc construction method based on the European PCa construction method.Japanese structural design standards of 2002 edition "design guide and explanation of assembly structure equivalent to cast-in-place structure" put forward the bearing capacity of assembly structure and requirements for normal use .

\section{Development of prefabricated concrete structures in China ${ }^{[3]}$}

In 1959, China introduced the thin-walled deep beam slab prefabricated concrete building of Soviet union.In 1979, the ministry of construction promulgated the first standard on prefabricated concrete structure, Interim provisions on structural design and construction of prefabricated large-board residential buildings,JGJ1-79.In the late 1980s, with the rise of commodity concrete, a large number of migrant workers flooded into cities as cheap labor force. The development of technology and equipment made the original prefabricated components lack cost-performance advantages.In the early 1990s, prefabricated concrete structures died out in China, and corresponding research, standards and norms were ignored.

By the 21st century, the advantages of prefabricated concrete structures have been reflected again, and Chinese prefabricated structures have begun to rise again.On October 1, 2014, "the technical specification for prefabricated concrete structures" (or JGJ1-2014) was officially implemented. In this regulation, the connection technology of prefabricated reinforced bars is mainly based on the technology of the United States and Japan.

\section{Development of prefabricated concrete structures in other countries}

In the 1980s, New Zealand began to try to use prefabricated frame structure and prefabricated shear wall structure in housing construction.In order to reduce the earthquake effect on building structure, New Zealand has developed the T node connection and cross node connection technology, which not only ensures the integrity of the structure but also effectively resists seismic force.

In 1960, Singapore adopted prefabricated concrete structures to build houses, which greatly shortened the planned construction period of construction projects by $22 \%$ to $55 \%$, greatly improving the production efficiency.

\section{Study on the connection technology of prefabricated concrete structures around the world}

Because there are a lot of horizontal and vertical joints in prefabricated structures, the main problem of this kind of structure is whether its overall performance can meet the needs of seismic resistance.It has been found by scholars at home and abroad that the node connection technology between prefabricated components is one of the key technologies of prefabricated structures.At present, the joint connection between prefabricated concrete structural members at home and abroad is mainly divided into two categories: wet connection and dry connection. The Wet connection mainly includes grouting joint of sleeve, grouting anchor connection. The dry connection mainly includes bolt connection, mechanical connection, etc.

\section{Wet connection}

\section{Sleeve grouting connection ${ }^{[4]}$}

Sleeve grouting connection way is to insert two reinforcement into a steel sleeve with concave grooves , and then inject high strength non-shrinkage grouting material into the inner cavity of the sleeve. When the grouting material is hardened, the reinforcement bars and the sleeve bond together.In this way, the stress is effectively transferred by grouting material between the grooves inside the sleeve and the ribs on the surface of the ribbed steel bar. 
Sleeve grouting technology is widely used in Europe, America, Japan and other countries. In the late 1960, Dr. Yu zhanshu of the United States invented the steel sleeve connector to solve the problem of joint connection in prefabricated concrete structures.And for the first time, the technology was applied to a 38-storey prefabricated building(Ala Moana Hotel, Honolulu, Hawaii) for the connection of prefabricated columns.

In 1972, the patent was purchased by a Japanese machining company and later tested and improved to a shorter Tops Sleeve.In 1984, Japanese experts and scholars developed a kind of sleeve named NMB.This type of socket the yield point is greater than $420 \mathrm{Mpa}$, tensile strength is greater than $600 \mathrm{mpa}$, the elongation is more than $6 \%$, can achieve a reliable connection in the reinforcement, were confirmed by the ministry of construction, widely used in prefabricated buildings.

At present, the commonly used sleeve grouting technology are divided into two types: full sleeve grouting connection and half sleeve grouting connection. Full sleeve grouting connection diagram is shown in figure 1, the rebars on both sides of the joint are covered by grouting material.As shown in the figure, the grouting hole is used for the injection of grouting material, and the grout vent hole is used for the exhaust when the grouting material is injected.This kind of sleeve grouting technology is most suitable for the connection of steel bar in precast concrete beam.

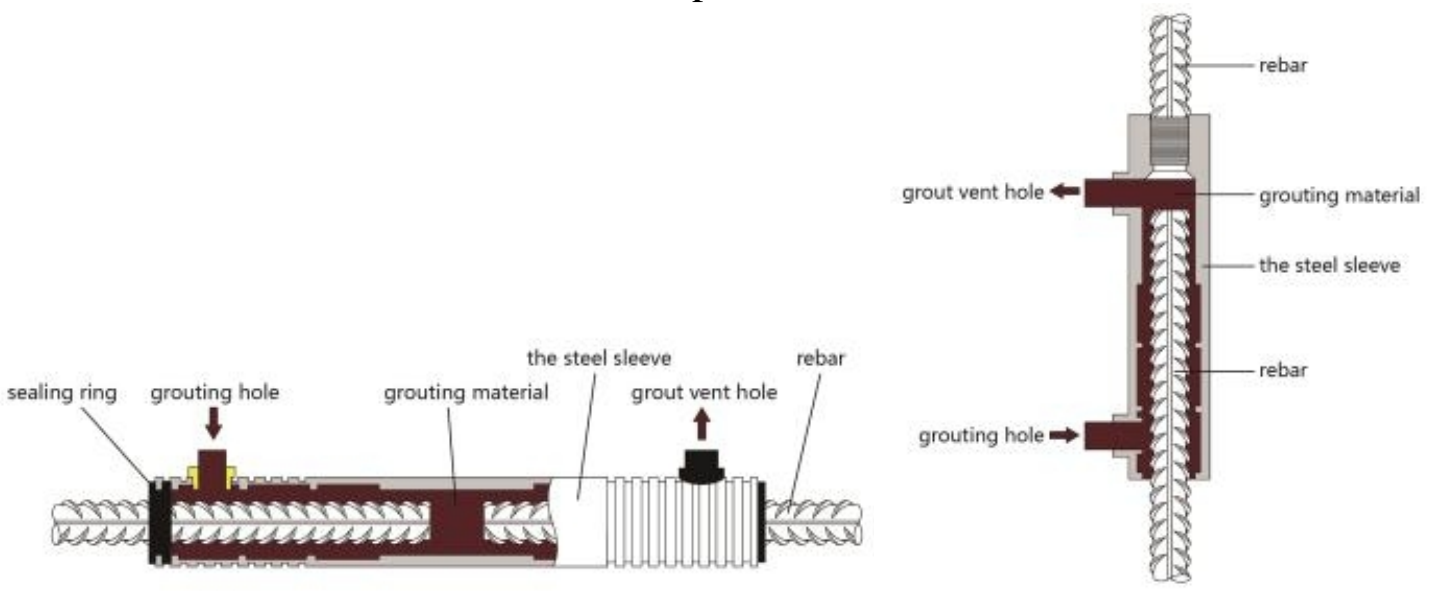

FIG. 1 full sleeve grouting

FIG. 2 half sleeve grouting

Half sleeve grouting connection diagram is shown in figure 2, this kind of joint is a combination of a straight threaded sleeve and a conventional sleeve with grooves in the inner cavity. When making concrete structural components in a factory, the end of the forced steel bar is screwed together with the straight threaded side of the sleeve, and no grouting.The other end of the sleeve is inserted into the embedded steel bar of the connecting member, and then grouting material is poured into the sleeve. This kind of connection method is mainly used for the connection of prefabricated shear wall reinforcement and prefabricated column reinforcement.

The above two kinds of sleeve grouting technologies are widely used in prefabricated concrete structures at home and abroad.This technology has been tested by many experts and scholars in various countries and has shown good mechanical performance.

\section{Grouting anchor connection ${ }^{[5]}$}

The slurry anchor connection is a form of reinforcing bar lap joint, as shown in figure 3.First, a hole is reserved at the bottom of the precast concrete member, and then the stress reinforcement of the adjacent concrete member is inserted into the hole and grouted in the hole. 


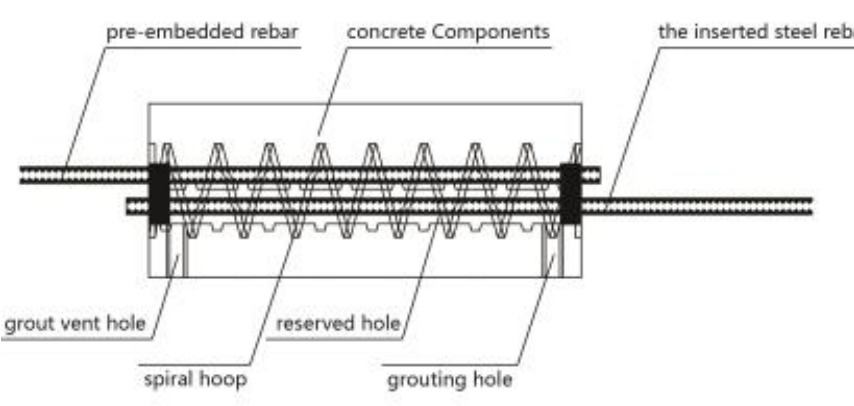

FIG.3 Grouting anchor connection methods

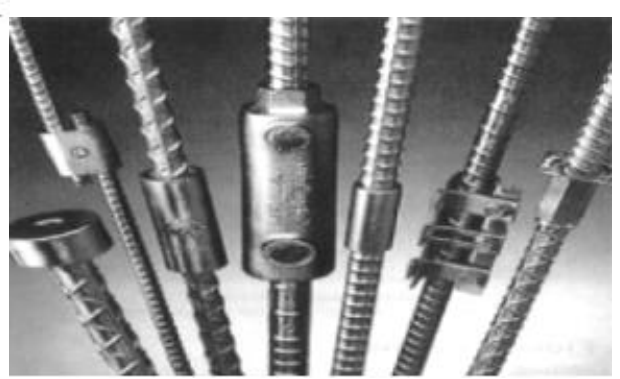

FIG.4 various mechanical connection

In 2008, jiang hongbin of Harbin Institute of Technology, China, invented the technology of "insert reserved hole grouting reinforcement connection" and obtained a patent.

\section{Dry connection}

\section{Bolt connection}

Bolt connection technology is to use the tensile and shear properties of high strength bolts to connect upper and lower prefabricated components into a whole.

\section{Mechanical connection}

Mechanical connection technology uses threaded sleeve to connect the steel bar on both sides of the joint and transfer the tensile stress of the steel bar through the mechanical bite force between components. This method has high joint strength, simple construction and no wet operation, which is beneficial to green field construction.

ERICO is a world-class steel company in the design and production of steel connections.Its steel connection method is widely used in building structures. The mechanical joints of several representative reinforcement bars are shown in FIG. 4.

\section{Conclusion}

(1)To sum up, the prefabricated concrete structure has the advantages of fast construction speed, excellent production, simple construction and less wet operation, so it can realize housing industrialization well.

(2) At present, there are many researches on the connection methods of prefabricated concrete structures, and they are mainly focused on the "wet connection", while there are few researches on the "dry connection".However, "dry connection" has the advantages of high joint strength, fast construction speed and no pollution, so it is recommended to strengthen the research in this area.

\section{References}

[1] Shuyu Lou.An overview of French industrial housing[J].Journal of Architecture,1985(2).

[2] Qinjian Jiang.Development of prefabricated concrete buildings at home and abroad[J].Journal of Building Technology.2010(12):74-77.

[3] Wei Zhang.Study on the technology of steel bar connection for assembling integral concrete structure[D].Xi'an:Chang 'an university,2015.

[4] Zhengxing Guo,Zhangfeng Zhu. The research results and application of prefabricated concrete shear wall structure[J].Journal of construction technology,2014(22):5-8,29.

[5] Junwei Ma,Wanyun Yin,Shoucheng Liu.Experimental Study on Anchor Connection of Reinforcement[J].Journal of architectural structures,2015(2):32-35,79.

Project Category:Qinhuangdao Science and Technology Support Project

Project Name:Application of Prestressed Technology in Prefabricated Building Structures 
Project approval number:201602A033 